\title{
PANOPHTHALMITIS IN A PREMATURE INFANT TREATED BY STREPTOMYCIN*
}

BY

\author{
L. B. SOMERVILLE-LARGE \\ DUBLIN
}

THE FOLLOWING is an account of panophthalmitis in a premature infant caused by bacillus proteus and treated with streptomycin.

The patient was a male premature child weighing $4 \mathrm{lbs} .5$ ozs. at birth. He was born in the Rotunda Hospital, and I was called to see him there in the Premature Ward when he was eleven days old. The ocular history was that inflammatory swelling in the lids of his left eye had commenced twenty-four hours previously and was rapidly increasing. He had had a superficial skin infection of his lower abdomen not reaching the umbilicus. This had cieared up rapidly on 30,000 units of penicillin injected over a twenty-four hour period, and was at that time completely cured. The umbilical cord had not fallen off. This separation occurs normally on the fifth or sixth day, but in this case was not complete until the twelfth. The baby was progressing satisfactorily, taking feeds well and putting on weight.

On examination of the condition I found an inflammatory oedema involving the lids of the left eye. This was well marked on the upper lid, but was only slightly apparent on the lower. The pre-auricular gland was not enlarged. The eye was proptosed. No conjunctival discharge was present. There was intense ciliary injection. The cornea was hazy. The anterior chamber was haif full of hypopyon which lay over the pupil, no pupillary margin being visible. There was no red reflex. The condition was diagnosed as panophthalmitis with a possible infection of the orbit. Panophthalmitis occurring after birth is usually regarded as duc to an infection of the umbilical cord. Its occurrence at this period of life is rare. No case has occurred in the Rotunda Hospital during the last twelve years (approximately 55,000 births). The right eye was normal.

Mr. R. R. Woods, the Ear, Nose and Throat Specialist to the hospital, kindly examined the case, but no source of possible nasal infection was found.

General examination revealed that the umbilicus was infected and also that there were two subcutaneous " abscesses" in the skin of the lower abdomen. These latter did not wholly resemble abscesses as they were not accompanied by signs of inflammation

- Received for publication, March 29, 1947. 
but appeared rather as small herniations through the abdominal wall. They were, however, aspirated for examination. A swab was taken from the umbilicus. Both examinations revealed bacillus proteus in pure culture. It was considered that the primary infection had taken place through the umbilicus.

Immediate operative treatment consisted in passing a fine Graefe knife into the orbit, and a search being made with a probe for pus. No pus was found. The proptosis remained unchanged. Three days later a needle was inserted into the anterior chamber and pus removed for bacterial examination. Here again bacillus proteus was grown in pure culture.

Immediate therapeutic treatment consisted in the administration of sulphadiazine by mouth and penicillin by injection. A total of fifteen grammes of the former and 170,000 units of the latter were given within the first six days, when they were discontinued and streptomycin started. The bacillus proteus proved bacteriologically to be resistant to penicillin.

During the first six days under the above therapy the ocular condition became steadily worse. Severe oedema developed in both

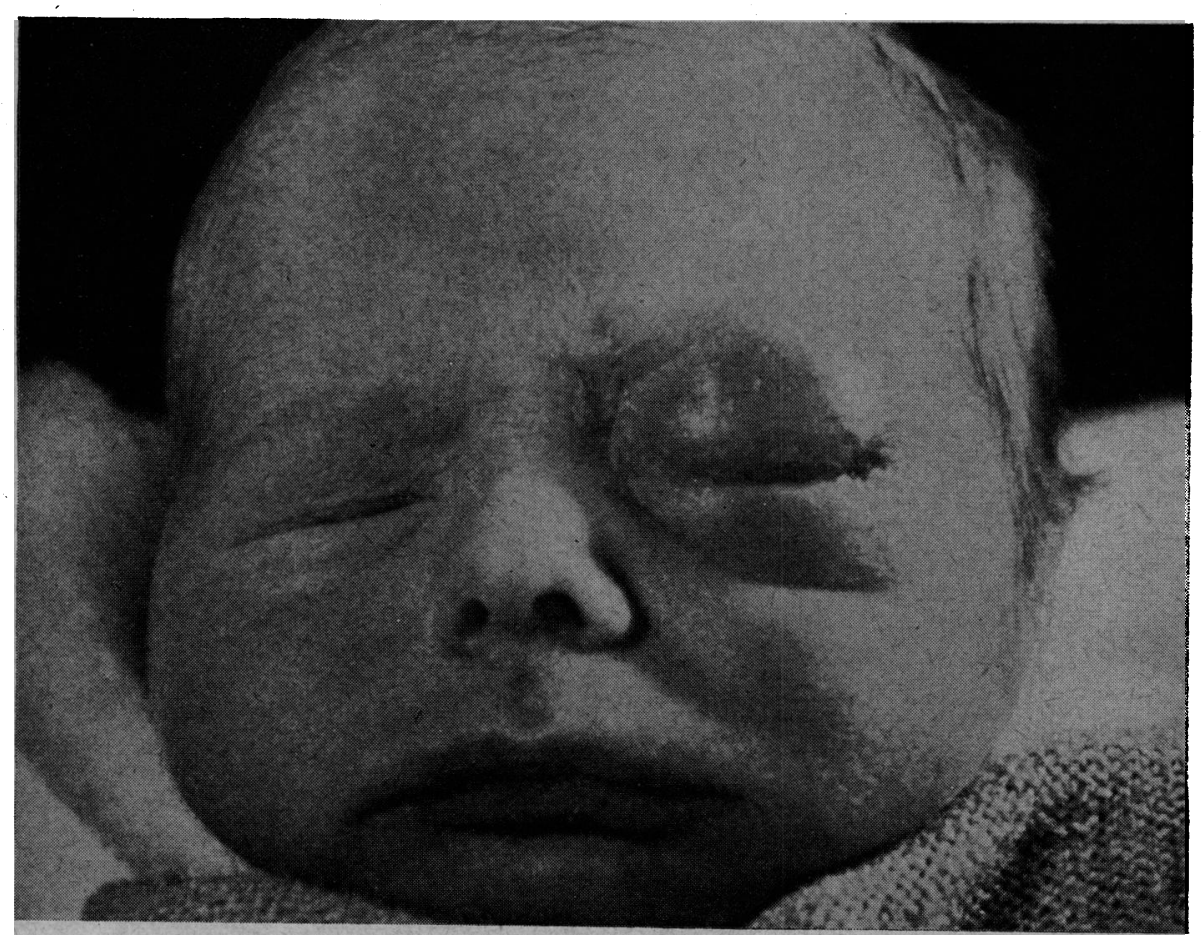

FIG. 1. 


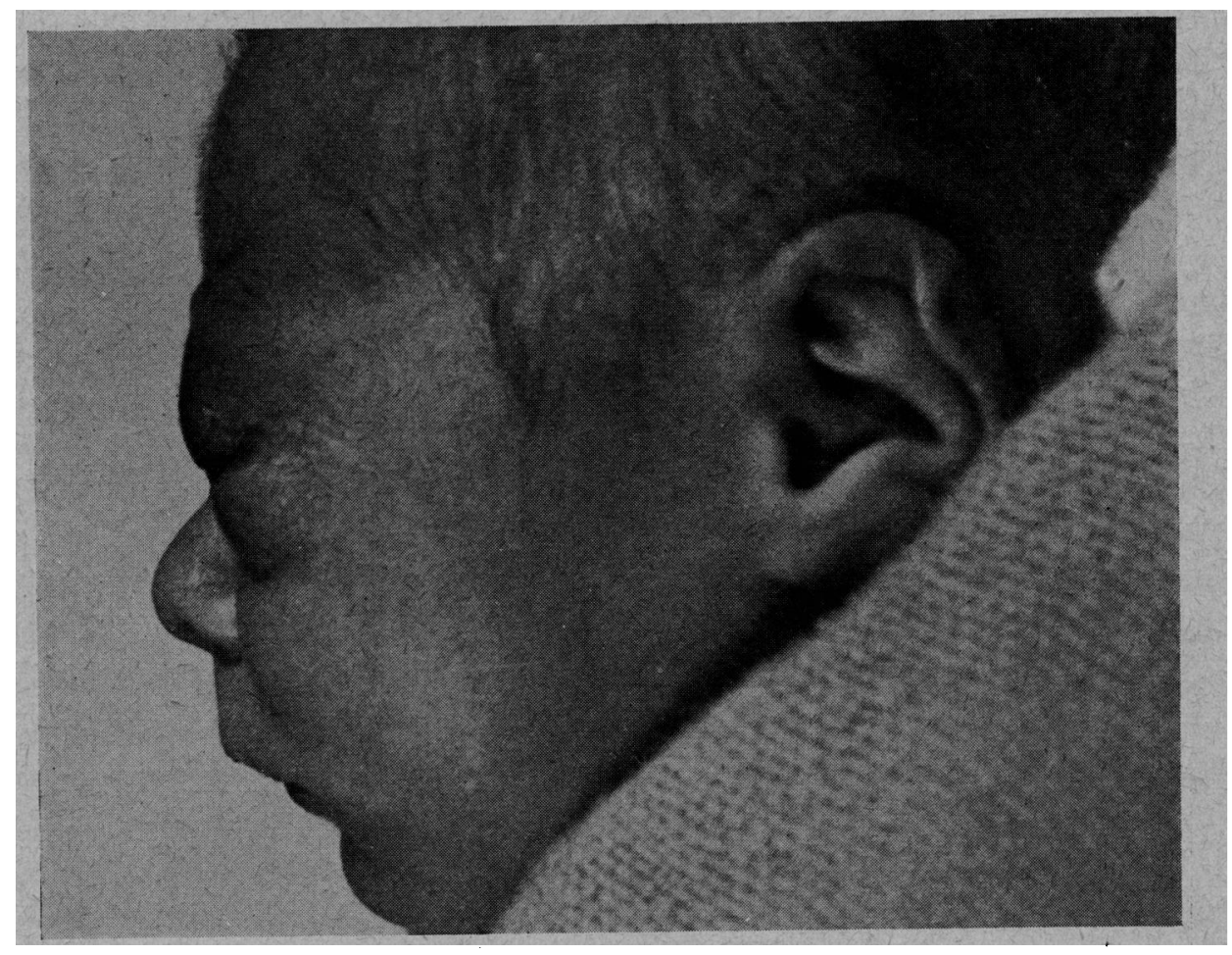

FIG. 2 .

lids. The conjunctival vessels became very congested and pannus commenced above. This pannus eventually covered the upper third of the cornea, and superficial blood vessels also encroached on the rest of the corneal periphery. The centre of the cornea developed a deep opacity. The child's general condition, however, remained highly satisfactory. There was no rise of temperature and weight was gained steadily.

Bacillus proteus is resistant to penicillin and the sulpha drugs but is highly sensitive to streptomycin. There was some delay in getting this drug, and no information as to dosage in a premature child could be obtained. Treatment was carried out as follows: One gramme of streptomycin was dissolved in 10 c.c. of sterile water and 1 c.c. was injected intramuscularly every three hours. This was continued for twenty-one hours, when the dose was reduced to 05 c.c., which was given three-hourly for sixty-six hours. Towards the end of this period the baby was bottle feeding so slowly that tube feeding had to be started. There was also a loss of weight (from 4 lbs. 14 ozs. to 4 lbs. 12 ozs.) and a rise in temperature $\left(998\right.$ to $\left.100^{\circ}\right)$ for two days. It was uncertain whether 
these symptoms were due to streptomycin, but some reduction was thought advisable. The dosage was therefore reduced to 0.25 c.c. every three hours, and this was continued until a total dosage of two and a half grammes had been given. The treatment with streptomycin covered a period of six and a half days.

Streptomycin was commenced at 3 p.m. one afternoon, and on the following morning for the first time there was a marked improvement in the clinical appearance. The lid oedema had greatly subsided and the eye was open. On the second day the skin folds had returned, and on the third all inflammation had gone from the lids leaving only some slight oedema. The condition of the eye itself remained unchanged. The subcutaneous abscesses disappeared soon after the streptomycin was commenced and required no local treatment.

On the ninth day from the commencement of streptomycin the globe perforated at about six mm. from the limbus between the inferior and lateral recti. Evisceration was carried out on the same day. The vitreous was found to be grossly infected. Swabs from the site of perforation, from the anterior chamber, and from the vitreous were taken. All were found to be sterile on culture.

The pathological report on the cornea and uveal tissue removed is as follows :-

The piece of cornea sectioned shows a considerable amount of proliferation of the epithelium. At one point this epithelium and Bowman's membrane have been broken through by a haemorrhage coming from a new vessel lying just under Bowman's membrane. A considerable number of new vessels can be seen at different levels, the majority lying anteriorly. Scattered chronic inflammatory cells are present mostly in the anterior third. At one point there is an aggregation of these cells involving the neighbourhood of Descemet's membrane and the posterior fourth of the adjacent substantia propria. In another area the whole corneal thickness is diffusely infiltrated with chronic inflammatory cells. The piece of uveal tissue consists mainly of choroid-a small part of the ciliary body is also present. The entire tissue is infiltrated uniformly, but not heavily, with chronic inflammatory cells, round, plasma and epithelioid. Some polymorphs are also present suggesting that the active inflammatory phase had not completely passed. Normal choroidal structure is unrecognisable. Proliferated pigment is present, passing through the section. Blood vessels are very numerous, the greater number containing erythrocytes. Some scattered haemorrhages are also present.

By the finding of bacillus proteus in the anterior chamber (in pure culture) prior to commencement of streptomycin treatment,'and by the negative cultures obtained from the highly infected 
globe after treatment, it may be inferred that this drug is capable of permeating the uveal tissue.

It is of importance that infection of the umbilical cord by a non-virulent organism is capable of producing panophthalmitis, and this without any general symptoms of septicaemia. Meningitis can, however, occur in infants from bacillus proteus, and this was a complication that was feared in this case.

The child is now three and a half months old, has remained in perfect health and is gaining weight steadily. No ill effects from the streptomycin treatment are apparent.

\section{Summary}

A case of panophthalmitis in a premature child following umbilical cord infection by bacillus proteus is described. An account is given of the treatment with streptomycin which is considered to have overcome the inflammation in the uveal tissue.

I am grateful to Dr. Ninian Falkiner, Master of The Rotunda, and Dr. R. Collis, Paedriatician to the hospital, for their advice and permission to publish this case. To Dr. Hinkston's invaluable assistance, and to Sister Moran who looked after the case I am greatly indebted. I am much obliged to Miss Thompson for her fine photographs, and to Dr. McCrea who kindly carried out the pathological examination.

\section{ON MENINGEAL REACTIONS IN SYMPATHETIC \\ OPHTHALMITIS * \\ L. Corcelle \\ AGEN, FRANCE}

IN $1934 \dagger$ I showed for the first time that meningeal reactions occurred in the course of sympathetic ophthalmitis, of which the interest is such as to warrant fresh emphasis. Before my paper appeared we had recognised the extra-ocular complications of sympathetic ophthalmitis, but their frequency was not very great and their description so very changeable that they were considered to be of secondary importance by most authors. However, Coppez, in his article on sympathetic ophthalmitis in the last. Traite d'ophtalmologie français, gave them a few lines and cast doubts on

* Received for publication, January, 1947.

+Contribution à l'etude de l'ophtalmie sympathique. L. Corcelle, Thése, Bordeaux, 1939. 